\title{
Expression of keratin 20 and its clinicopathological significance in intrahepatic cholangiocarcinoma
}

\author{
JI EUN CHOI ${ }^{1}$, SANG JAE NOH ${ }^{1}$, JU HYUNG LEE ${ }^{2}$, JUN SANG BAE ${ }^{1}$, HYUN HEE CHU ${ }^{1}$, HO SUNG PARK ${ }^{1}$, \\ KYU YUN JANG ${ }^{1}$, MYOUNG JA CHUNG ${ }^{1}$, MYOUNG JAE KANG ${ }^{1}$, DONG GEUN LEE ${ }^{1}$ and WOO SUNG MOON ${ }^{1}$ \\ Departments of ${ }^{1}$ Pathology and ${ }^{2}$ Preventive Medicine, Chonbuk National University, \\ Medical School and Research Institute for Endocrine Sciences, Jeonju, Jeonbuk 561-756, Republic of Korea
}

Received February 28, 2012; Accepted June 6, 2012

DOI: $10.3892 / \mathrm{ol} .2012 .756$

\begin{abstract}
Although the expression of keratin 7 (K7) and K20 is considered to be a useful factor in the differential diagnosis of intrahepatic cholangiocarcinoma (ICC) and metastatic colorectal carcinoma (CRC) of the liver, a proportion of typical ICC retains K20 expression. The frequency and biological significance of K20 expression in ICC remains unclear. We analyzed the expression of K7, K19 and K20 in 66 surgically resected liver tumors consisting of 46 ICCs and 20 metastatic CRCs of the liver and 20 corresponding primary CRCs. In the 46 ICCs, K7, K19 and K20 were expressed in 40 (87\%), 45 (98\%) and $16(35 \%)$ cases, respectively. K7, K19 and K20 were expressed in $1(5 \%), 20(100 \%)$ and $16(80 \%)$ of the 20 primary CRCs and $2(10 \%), 20(100 \%)$ and $16(80 \%)$ of the 20 metastatic CRCs, respectively. A combined K7/K20 profile was identified as a good predictor for differentiating ICC and metastatic CRC. K20 expression in ICC was significantly associated with male gender $(\mathrm{P}=0.034)$, hilar location $(\mathrm{P}=0.026)$, intraductal papillary type $(\mathrm{P}=0.006)$, intestinal phenotype $(\mathrm{P}<0.001)$ and MUC2 expression $(\mathrm{P}=0.008)$. Univariate analysis identified that poor patient survival was significantly associated with histological grade $(\mathrm{P}=0.020)$, invasion depth $(\mathrm{P}=0.005)$, lymph node metastasis $(\mathrm{P}=0.012)$, tumor stage $(\mathrm{P}=0.004)$ and vessel invasion $(\mathrm{P}=0.023)$. The tumor stage $(\mathrm{P}=0.002)$ was a poor independent prognostic indicator, while MUC6 expression $(\mathrm{P}=0.036)$ was a good independent prognostic indicator. The survival rate in patients with K20-positive ICC was lower compared to that of patients with K20-negative ICC, but was not statistically significant. Furthermore, the combined K7/ K20 immunophenotype was identified to be useful for differentiating ICC and metastatic CRC. K20-positive ICC displays specific characteristics with regards to tumor location and
\end{abstract}

Correspondence to: Professor Woo Sung Moon, Department of Pathology, Chonbuk National University, Medical School and Research Institute for Endocrine Sciences, 2-20 Keumamdong San, Jeonju, Jeonbuk 561-756, Republic of Korea

E-mail: mws@chonbuk.ac.kr

Key words: keratin, cholangiocarcinoma, mucin, colorectal carcinoma histological subtype. Additionally, MUC6 expression in ICC is a good independent prognostic factor, while $\mathrm{K} 20$ expression is more often associated with aggressive biological behavior.

\section{Introduction}

Keratins are cytoskeletal intermediate filaments, which are present in normal and malignant epithelial cells. Various keratins are expressed in a tissue- and differentiation-specific manner; therefore, every epithelial cell can be categorized by the specific pattern of its keratin expression profile (1). Keratin 20 (K20) is consistently expressed in primary and metastatic colorectal carcinoma (CRC) and demonstrates variable reactivity in gastric and pancreatic cancer (2). Immunohistochemical analysis for K7, K19 and K20 is considered useful when making a differential diagnosis of primary and metastatic carcinomas of the liver $(3,4)$. In one study, $97 \%$ of cholangiocarcinoma (CC) and $3 \%$ of metastatic CRC tissues were diffusely positive for $\mathrm{K} 7,77 \%$ of $\mathrm{CC}$ and $64 \%$ of metastatic CRC tissues were diffusely positive for K19, and $10 \%$ of $\mathrm{CC}$ and $74 \%$ of metastatic CRC tissues were diffusely positive for $\mathrm{K} 20$ (3). It was identified that the $\mathrm{K} 7^{+} / \mathrm{K} 20^{-}$profile has a $100 \%$ positive predictive value (PPV) for $\mathrm{CC}$ and the $\mathrm{K} 7 / \mathrm{K} 20^{+}$ profile has a $93 \%$ PPV for metastatic CRC (4). In previous studies, a proportion of typical intrahepatic cholangiocarcinoma (ICC) retained K20 expression (3-5); however, the frequency and clinicopathological significance of K20 expression in ICC remains unclear.

In this study, we evaluated the expression of K7, K19 and K20 in 46 ICCs and 20 metastatic CRCs of the liver and 20 corresponding primary $\mathrm{CRCs}$, and analyzed the clinicopathological characteristics of $\mathrm{K} 20^{+}$ICC. We also examined the correlation between $\mathrm{K} 20$ expression and mucin phenotype in ICC.

\section{Patients and methods}

Patients. We examined 66 surgically resected liver tumors consisting of 46 ICCs obtained from 1998 to 2010, and 20 metastatic CRCs of the liver and the corresponding primary CRCs obtained from 1998 to 2005 at Chonbuk National University Hospital, Jeonju, Korea. In each case, clinicopathological features, including patient age at diagnosis, gender, vessel and 

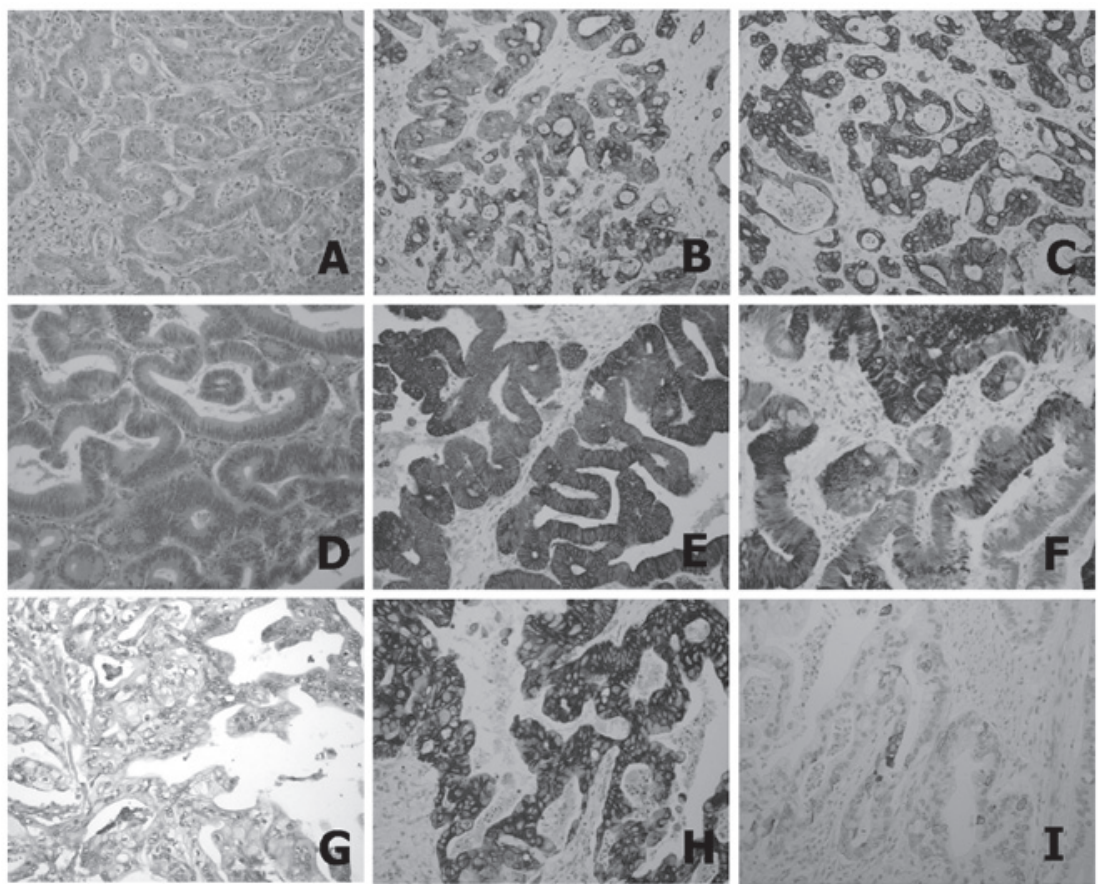

Figure 1. Pancreatobiliary type CC (A) H\&E staining, (B) immunostaining for K7 and (C) immunostaining for K20. Almost all cancer cells are positive for $\mathrm{K} 7$ and $\mathrm{K} 20 . \mathrm{K} 7 / \mathrm{K} 19^{+} / \mathrm{K} 20^{+}$intestinal type CC (D) H\&E staining, (E) positive immunostaining for K19 and (F) positive immunostaining for K20. Gastric type CC (G) H\&E staining, (H) positive immunostaining for K7 and (I) negative immunostaining for K20. CC, cholangiocarcinoma; H\&E, hematoxylin and eosin; K, keratin.

neural invasion, and follow-up data were obtained from hospital records. Tumors were staged according to the 2010 American Joint Committee on Cancer tumor-node-metastasis (TNM) classification (6). Grade and phenotype of ICCs were classified according to WHO classification (7) and mucin expression profiles. The follow-up period was determined from the date of initial surgery to the date of the last follow-up or mortality. This study was approved by the ethics committees of Chonbuk National University.

Immunohistochemical staining. A formalin-fixed, paraffin-embedded, representative $4-\mu \mathrm{m}$ section was obtained from each of the 46 ICC, 20 primary CRC and 20 metastatic CRC specimens. Immunohistochemical staining was performed by polymer intense detection system using the Bond-Max Automatic stainer (Leica Microsystems Inc., Bannockburn, IL, USA) in accordance with the manufacturer's instructions. Following antigen retrieval in a microwave oven for $10 \mathrm{~min}$ in $0.01 \mathrm{~mol}$ citrate buffer $(\mathrm{pH} 9.0)$, cells were incubated with anti-K7 (Novocastra, Wetzlar, Germany), anti-K19 (Dako, Glostrup, Denmark), anti-K20, anti-MUC2, anti-MUC 5AC, anti-MUC 6 (Novocastra) and anti-CD10 (Cell Marque, Rocklin, CA, USA) antibody for $30 \mathrm{~min}$.

Immunohistochemical analysis and classification of epithelial phenotypes. The samples that were subjected to immunostaining were rated according to a score calculated by multiplying the cancer area of the stain with the intensity of the stain. The area of staining was scored as follows: $0(<10 \%)$, $1(10-69 \%)$ or $2(\geq 70 \%)$. The intensity of the cell cytoplasmic staining was grouped into four categories: 0, no immunostaining; 1 , weak; 2 , moderate; 3 , strong. If the score was $\geq 1$, the tumor was considered positive; otherwise, the tumor was considered negative. The classification of the epithelial phenotypes was based on morphological features of the tumor cells in addition to mucin expression patterns, which were defined as follows: a) intestinal type, characterized by positive staining for MUC2 or CD10; b) gastric type, characterized by positive staining for MUC5AC or MUC6; c) mixed type, characterized by positive staining for both gastric and intestinal mucin; d) undifferentiated type, characterized by no staining for any applied markers.

Statistical analysis. The SPSS version 15.0 statistical software program (SPSS, Chicago, IL, USA) was used for the statistical analyses. The clinicopathological characteristics were compared with the expression of K7, K19 and K20 using the Chi-square test. A Cox proportional hazard regression analysis was conducted to estimate the impact of clinicopathological factors on patient survival. Survival curves were calculated using the Kaplan-Meier method and the differences between the curves were analyzed using the log-rank test. $\mathrm{P}<0.05$ was considered to indicate a statistically significant difference.

\section{Results}

Clinicopathological data. The 46 ICC patients consisted of $31(67.4 \%)$ males and $15(32.6 \%)$ females. According to the location of the tumor in the biliary tract, 16 (34.8\%) ICCs were classified as hilar and $30(65.2 \%)$ as peripheral types. Based on gross morphology, 27 (58.7\%) ICCs were classified as mass-forming, $11(23.9 \%)$ as intraductal papillary and eight $(17.4 \%)$ as periductal infiltrative type. A total of $14(30.4 \%)$ were well-differentiated, 20 (43.5\%) were moder- 
Table I. Correlation between K20 expression and clinicopathological factors in ICC.

\begin{tabular}{|c|c|c|c|c|}
\hline $\begin{array}{l}\text { Clinicopathological } \\
\text { factors }\end{array}$ & $\begin{array}{c}\mathrm{K} 20^{+}(\%) \\
\mathrm{n}=16\end{array}$ & $\begin{array}{c}\mathrm{K} 20^{-}(\%) \\
\mathrm{n}=30\end{array}$ & $\begin{array}{c}\text { Total }(\%) \\
n=46\end{array}$ & P-value \\
\hline Age, mean \pm SD (years) & $62.3 \pm 8.4$ & $61.7 \pm 9.1$ & $61.9 \pm 8.8$ & 0.832 \\
\hline \multicolumn{5}{|l|}{ Gender } \\
\hline Female & $2(12.5)$ & $13(43.3)$ & $15(32.6)$ & \multirow[t]{2}{*}{0.034} \\
\hline Male & $14(87.5)$ & $17(56.7)$ & $31(67.4)$ & \\
\hline \multicolumn{5}{|l|}{ Location } \\
\hline Hilar & $9(56.3)$ & $7(23.3)$ & $16(34.8)$ & \multirow[t]{2}{*}{0.026} \\
\hline Peripheral & $7(43.8)$ & $23(76.7)$ & $30(65.2)$ & \\
\hline \multicolumn{5}{|l|}{ Macroscopic type } \\
\hline Intraductal papillary & $8(50.0)$ & $3(10.0)$ & $11(23.9)$ & \multirow[t]{3}{*}{0.006} \\
\hline Periductal infiltrative & $3(18.8)$ & $5(16.7)$ & $8(17.4)$ & \\
\hline Mass-forming & $5(31.3)$ & $22(73.3)$ & $27(58.7)$ & \\
\hline \multicolumn{5}{|l|}{ Differentiation } \\
\hline Well & $8(50.0)$ & $6(20.0)$ & $14(30.4)$ & \multirow[t]{3}{*}{0.081} \\
\hline Moderate & $6(37.5)$ & $14(46.7)$ & $20(43.5)$ & \\
\hline Poor & $2(12.5)$ & $10(33.3)$ & $12(26.1)$ & \\
\hline \multicolumn{5}{|l|}{ T category } \\
\hline Tis, 1 & $9(56.3)$ & $12(40.0)$ & $21(45.7)$ & \multirow[t]{2}{*}{0.292} \\
\hline $\mathrm{T} 2,3,4$ & $7(43.2)$ & $18(60.0)$ & $25(54.3)$ & \\
\hline \multicolumn{5}{|l|}{$\mathrm{N}$ category } \\
\hline N0 & $14(87.5)$ & $26(86.7)$ & $40(87.0)$ & \multirow[t]{2}{*}{0.936} \\
\hline N1 & $2(12.5)$ & $4(13.3)$ & $6(13.0)$ & \\
\hline \multicolumn{5}{|l|}{ M category } \\
\hline M0 & $15(93.8)$ & $28(93.3)$ & $43(93.5)$ & \multirow[t]{2}{*}{0.957} \\
\hline M1 & $1(6.3)$ & $2(6.7)$ & $3(6.5)$ & \\
\hline \multicolumn{5}{|l|}{ Stage } \\
\hline $0, \mathrm{I}$ & $8(50.0)$ & $12(40.0)$ & $20(43.5)$ & \multirow[t]{2}{*}{0.514} \\
\hline II, III, IV & $8(50.0)$ & $18(60.0)$ & $26(56.5)$ & \\
\hline \multicolumn{5}{|l|}{ Neural invasion } \\
\hline Absence & $15(93.8)$ & $23(76.7)$ & $38(82.6)$ & \multirow[t]{2}{*}{0.145} \\
\hline Presence & $1(6.3)$ & $7(23.3)$ & $8(17.4)$ & \\
\hline \multicolumn{5}{|l|}{ Vessel invasion } \\
\hline Absence & $11(68.8)$ & $17(56.7)$ & $28(60.9)$ & \multirow[t]{2}{*}{0.424} \\
\hline Presence & $5(31.3)$ & $13(43.3)$ & $18(39.1)$ & \\
\hline \multicolumn{5}{|l|}{ Epithelial type } \\
\hline I & $8(50.0)$ & $0(0.0)$ & $8(17.4)$ & \multirow[t]{3}{*}{$<0.001$} \\
\hline $\mathrm{G}+$ mixed & $0(0.0)$ & $5(16.7)$ & $5(10.8)$ & \\
\hline $\mathrm{Pb}+$ undifferentiated & $8(50.0)$ & $25(83.3)$ & $33(71.8)$ & \\
\hline
\end{tabular}

$\mathrm{K}$, keratin; ICC, intrahepatic cholangiocarcinoma. SD, standard deviation; T, tumor; N, node; M, metastasis; I, intestinal; G, gastric; $\mathrm{Pb}$, pancreatobiliary.

ately differentiated and $12(26.1 \%)$ were poorly differentiated. Additionally, 5 of the 46 ICC patients had clonorchiasis and 5 had intrahepatic bile duct stones.

Immunohistochemical results. K7, K19 and K20 were expressed in $40(87.0 \%), 45(97.8 \%)$ and $16(34.8 \%)$ of the 46 ICCs, respectively (Fig. 1). CD10, MUC2, MUC5AC and MUC6 were expressed in 13 (28.3\%), 10 (21.7\%), 19 (41.3\%) and $6(13.0 \%)$ of the 46 ICCs, respectively. K7, K19 and K20 were expressed in $1(5 \%), 20(100 \%)$ and $16(80 \%)$ of the 20 primary CRCs and 2 (10\%), 20 (100\%) and $16(80 \%)$ of the 20 metastatic CRCs, respectively. One K7-negative primary $\mathrm{CRC}$ changed to positive in metastatic CRC, while 4 K20-negative CRCs changed to K20-positive in metastatic CRCs. According to the morphology of tumor cells and mucin phenotype, the 46 ICCs were divided into 32 (69.6\%) pancrea- 
Table II. Correlation between K20 expression and mucin phenotype of ICC.

\begin{tabular}{|c|c|c|c|c|}
\hline \multirow{2}{*}{$\begin{array}{l}\text { Mucin } \\
\text { phenotype }\end{array}$} & \multirow{2}{*}{$\begin{array}{c}\text { No. }(\%) \\
n=46\end{array}$} & \multicolumn{2}{|c|}{ K20 expression (\%) } & \multirow[b]{2}{*}{ P-value } \\
\hline & & Negative, $n=30$ & Positive, $n=16$ & \\
\hline \multicolumn{5}{|l|}{ CD10 } \\
\hline Negative & $33(71.7)$ & $21(70.0)$ & $12(75.0)$ & 0.720 \\
\hline Positive & $13(28.3)$ & $9(30.0)$ & $4(25.0)$ & \\
\hline \multicolumn{5}{|l|}{ MUC2 } \\
\hline Negative & $36(78.3)$ & $27(90.0)$ & $9(56.3)$ & 0.008 \\
\hline Positive & $10(21.7)$ & $3(10.0)$ & $7(43.8)$ & \\
\hline \multicolumn{5}{|l|}{ MUC5AC } \\
\hline Negative & $27(58.7)$ & $16(53.3)$ & $11(68.8)$ & 0.312 \\
\hline Positive & $19(41.3)$ & $14(46.7)$ & $5(31.3)$ & \\
\hline \multicolumn{5}{|l|}{ MUC6 } \\
\hline Negative & $40(87.0)$ & $27(90.0)$ & $13(81.3)$ & 0.401 \\
\hline Positive & $6(13.0)$ & $3(10.0)$ & $3(18.8)$ & \\
\hline
\end{tabular}

$\mathrm{K}$, keratin; ICC, intrahepatic cholangiocarcinoma.

Table III. Sensitivity, specificity and PPV of K7/20 profiles in ICC and metastatic CRC.

\begin{tabular}{|c|c|c|c|c|c|c|}
\hline \multirow{2}{*}{$\begin{array}{l}\mathrm{K} 7 / \mathrm{K} 20 \\
\text { expression }\end{array}$} & \multicolumn{3}{|c|}{$\mathrm{ICC}$} & \multicolumn{3}{|c|}{ Metastatic CRC } \\
\hline & Sensitivity (\%) & Specificity (\%) & PPV & Sensitivity (\%) & Specificity (\%) & PPV \\
\hline $\mathrm{K} 7^{+} / \mathrm{K} 20^{-}$ & 58.7 & 100.0 & 100.0 & 0.0 & 41.3 & 0.0 \\
\hline $\mathrm{K} 7^{-} / \mathrm{K} 20^{+}$ & 6.5 & 20.0 & 15.8 & 80.0 & 93.5 & 84.2 \\
\hline $\mathrm{K}{ }^{+} / \mathrm{K} 20^{+}$ & 28.3 & 90.0 & 86.7 & 20.0 & 71.7 & 13.3 \\
\hline
\end{tabular}

PPV, predictive positive value; K, keratin; ICC, intrahepatic cholangiocarcinoma; CRC, colorectal carcinoma.

tobiliary, $8(17.4 \%)$ intestinal, $2(4.3 \%)$ gastric, $3(6.5 \%)$ mixed and $1(2.2 \%)$ unclassified type.

Correlation between $K 20$ expression and clinicopathological features of ICC. The correlations between K20 expression in ICCs and clinicopathological features are summarized in Table I. K20 expression in ICC was significantly associated with male gender $(\mathrm{P}=0.034)$, hilar location $(\mathrm{P}=0.026)$, intraductal papillary type $(\mathrm{P}=0.006)$ and intestinal epithelial type $(\mathrm{P}<0.001)$. No significant correlation was identified between K20 expression and differentiation, invasion depth, lymph node metastasis, distant metastasis, overall stage, neural invasion and vessel invasion. On comparison with the mucin phenotype of ICC, K20 expression was significantly associated with MUC2 expression ( $\mathrm{P}=0.008)$ (Table II). Although there was no statistical significance between MUC2 expression and the intraductal papillary type, five of the 11 (45\%) intraductal papillary types displayed MUC2 expression, indicating a close correlation between these two factors.

K7/K20 profiles in differential diagnosis of ICC and metastatic CRC of the liver. The sensitivity, specificity and PPV of the different K7/K20 immunophenotypes for ICC and metastatic CRC are demonstrated in Table III. The $\mathrm{K}^{+} / \mathrm{K} 20$ immunophenotype had a $100 \%$ PPV for the diagnosis of ICC and the $\mathrm{K} 7 / \mathrm{K} 20^{+}$immunophenotype had an $84.2 \%$ PPV for the diagnosis of metastatic $\mathrm{CRC}$. The $\mathrm{K} 7^{+} / \mathrm{K} 20^{+}$immunophenotype had an $86.7 \%$ and $13.3 \%$ PPV for the diagnosis of ICC and metastatic $\mathrm{CRC}$, respectively.

Patient outcome. The median follow-up period for patients with ICC was 28.8 months and the median survival time was 30.0 months. There was a total of six mortalities from ICC and one from pancreatitis. Univariate Cox survival analysis of the 46 ICCs identified that invasion depth $(\mathrm{P}=0.005)$, lymph node metastasis $(\mathrm{P}=0.012)$, tumor stage $(\mathrm{P}=0.004)$ and vessel invasion $(\mathrm{P}=0.023)$ were significantly associated with poor patient survival, and that MUC6 expression $(\mathrm{P}=0.044)$ had a strong correlation with patient survival. Tumor stage $(\mathrm{P}=0.002)$ was associated with poor patient survival, while MUC6 expression $(\mathrm{P}=0.036)$ was correlated with good patient survival as revealed by multivariate Cox survival analysis. The median survival time of patients with K20-positive ICC was $22.9 \pm 7.7$ months. The median survival time of patients 
Table IV. Univariate and multivariate Cox proportional hazard analysis of the factors associated with 46 ICC patients.

\begin{tabular}{|c|c|c|c|c|c|c|c|}
\hline \multirow{2}{*}{$\begin{array}{l}\text { ICC associated } \\
\text { factors }\end{array}$} & \multirow[b]{2}{*}{ No. $(\%)$} & \multicolumn{3}{|c|}{ Univariate model } & \multicolumn{3}{|c|}{ Multivariate model } \\
\hline & & HR & $95 \% \mathrm{CI}$ & P-value & HR & $95 \% \mathrm{CI}$ & P-value \\
\hline \multicolumn{8}{|l|}{ Differentiation } \\
\hline Well & $14(30.4)$ & 1 & & & & & \\
\hline Moderate & $20(43.5)$ & 1.5 & $0.58-3.92$ & 0.405 & & & \\
\hline Poor & $12(26.1)$ & 3.49 & $1.22-9.97$ & 0.020 & & & \\
\hline \multicolumn{8}{|l|}{$\mathrm{T}$ category } \\
\hline Tis, 1 & $21(45.7)$ & 1 & & & & & \\
\hline $\mathrm{T} 2,3,4$ & $25(54.3)$ & 3.32 & $1.44-7.63$ & 0.005 & & & \\
\hline \multicolumn{8}{|l|}{$\mathrm{N}$ category } \\
\hline N0 & $40(87.0)$ & 1 & & & & & \\
\hline N1 & $6(13.0)$ & 3.41 & $1.31-8.87$ & 0.012 & & & \\
\hline \multicolumn{8}{|l|}{ Stage } \\
\hline $0, \mathrm{I}$ & $20(43.5)$ & 1 & & & 1 & & \\
\hline II, III, IV & $26(56.5)$ & 3.57 & $1.51-8.43$ & 0.004 & 3.83 & $1.61-9.15$ & 0.002 \\
\hline \multicolumn{8}{|l|}{ Vessel invasion } \\
\hline Absence & $28(60.9)$ & 1 & & & & & \\
\hline Presence & $18(39.1)$ & 2.51 & $1.13-5.56$ & 0.023 & & & \\
\hline \multicolumn{8}{|l|}{ MUC6 } \\
\hline Positive & $6(13.0)$ & 0.12 & $0.02-0.95$ & 0.044 & 0.11 & $0.02-0.87$ & 0.036 \\
\hline Negative & $40(87.0)$ & 1 & & & 1 & & \\
\hline \multicolumn{8}{|l|}{ K7 } \\
\hline Positive & $40(87.0)$ & 0.81 & $0.30-2.16$ & 0.674 & & & \\
\hline Negative & $6(13.0)$ & 1 & & & & & \\
\hline \multicolumn{8}{|l|}{ K19 } \\
\hline Positive & 45 (98.7) & 0.32 & $0.04-2.45$ & 0.271 & & & \\
\hline Negative & $1(1.3)$ & 1 & & & & & \\
\hline \multicolumn{8}{|l|}{$\mathrm{K} 20$} \\
\hline Positive & $16(34.8)$ & 1.18 & $0.54-2.57$ & 0.685 & & & \\
\hline Negative & $30(65.2)$ & 1 & & & & & \\
\hline
\end{tabular}

Multivariate model was analyzed using stepwise methods including age, gender, macroscopic type, differentiation, stage and MUC6 expression. ICC, intrahepatic cholangiocarcinoma; HR, hazard ratio; CI, confidence interval; T, tumor; N, node; K, keratin.

with K20-negative ICC was 42.9 \pm 18.9 months. The 1-, 3- and 5 -year survival rates in patients with K20-positive ICC were lower (41, 33 and $33 \%$, respectively) than those of patients with K20-negative ICC (54, 42 and 34\%, respectively). However, no significant survival difference was observed between patients with K20-positive and K20-negative ICC as demonstrated by a Kaplan-Meier analysis (Table IV).

\section{Discussion}

Previous studies have investigated the use of $\mathrm{K}$ immunostaining in differentiating ICC from metastatic malignant tumor from other primary sites $(2-4,8)$. However, with respect to the clinicopathological and biological significance, immunohistochemical studies of $\mathrm{K}$ expression remain insufficient. K20 expression in ICC is significantly associated with gender, tumor location, intraductal papillary type, intestinal pheno- type and MUC2 expression. Although a proportion of ICC cases express $\mathrm{K} 20$, combined immunostaining for $\mathrm{K} 7$ and $\mathrm{K} 20$ has been identified to be useful in differentiating ICC from metastatic CRC. Advanced tumor stage is a poor independent prognostic indicator, while MUC6 expression is a good independent prognostic indicator. Additionally, K20 expression was significantly associated with intraductal papillary growth type and MUC2 expression.

ICC can be categorized into three macroscopic growth types: mass-forming, periductal infiltrative and intraductal papillary. Intraductal papillary ICC differs from other types as it has better prognosis and secreted mucin subtypes (7). It is considered to be the biliary counterpart of intraductal mucinous neoplasms of the pancreas $(9,10)$. Immunohistochemically, papillary CCs are characterized by the frequent co-expression of MUC2, CDX2 and K20 (9). Zen et al proposed three carcinogenetic pathways characterized by different immuno- 
phenotypes of mucin and $\mathrm{K}$ expression. Intraductal papillary neoplasms of the bile duct were characterized by an intestinal phenotype (MUC2 ${ }^{+} / \mathrm{K} 20^{+}$), and by carcinogenesis leading to tubular adenocarcinoma with increasing MUC1 expression (11). Genetic alterations and molecular changes vary between papillary ICC and non-papillary ICC (12-14). The close correlation between ICC of intraductal papillary type and $\mathrm{K}_{20} 0^{+} \mathrm{MUC}^{+}$in this study supports the hypothesis that the intraductal papillary type may be different from other types of ICC. In this study, we also identified that K20-positive ICC was closely associated with tumor location. This is in accordance with previous studies, which demonstrated that K20 expression correlated with hilar type ICC $(4,5)$. The $\mathrm{K} 20$-positive rate varies according to the sites of origin of $\mathrm{CC}$ and appears to increase from peripheral to large extrahepatic bile ducts CC (4). Guedj et al revealed that hilar and peripheral $\mathrm{CC}$ demonstrate different morphological features and display specific protein profiles, suggesting that hilar and peripheral CC may be considered to be distinct tumors that follow specific molecular pathways of carcinogenesis (15).

Differentiating between ICC and metastatic CRC of the liver may be difficult by means of conventional histological examination. The use of $\mathrm{K} 7$ and $\mathrm{K} 20$ immunostaining is relevant for the differential diagnosis of ICC and metastatic CRC, due to the specific $\mathrm{K}$ profile of metastatic CRC $\left(\mathrm{K} 7^{-} / \mathrm{K} 20^{+}\right)$, which differs from that of ICC $\left(\mathrm{K}^{+} / \mathrm{K} 20^{-}\right)(2-5)$. In the present study, K20 expression was observed in $35 \%$ of the 46 ICC patients, which was similar to earlier studies of K20 expression in $10-50 \%$ of ICCs $(2,3,5,8)$. However, this result differs from other studies, in which K20 expression was evident in up to $71 \%$ of ICC tissues (4). This discrepancy may be explained in part by the varied criteria for positivity, the different antibodies used and detection methods applied. In our study, K19 was expressed in $97.8 \%$ of ICC and $100 \%$ of primary and metastatic CRC cases. K19 is normally expressed in the lining of the gastroenteropancreatic and hepatobiliary tracts (16). Therefore, K19 may not be useful in the differential diagnosis of ICC from metastatic CRC. Similar to previous studies (2-5), K7 was rarely positive, while in the present study K20 was usually positive in metastatic CRC. We identified that the combined K7/K20 immunophenotype was useful when making a differential diagnosis of ICC and metastatic $\mathrm{CRC}$. The $\mathrm{K}^{+} / \mathrm{K} 20^{-}$profile was specific for ICC (100\%), when compared with that of metastatic CRC, and the PPV of this phenotype for ICC diagnosis was $100 \%$. In comparison, the $\mathrm{K} 7 / \mathrm{K} 20^{+}$profile was specific for metastatic CRC $(93.5 \%)$, when compared with that of ICC, and the PPV of this phenotype for metastatic CRC diagnosis was $84.2 \%$. However, a precise analysis of clinicopathological features and the use of additional relevant markers are also required in cases of $\mathrm{K} 7^{+} / \mathrm{K} 20^{+}$tumors for correct diagnosis.

ICC is the second most common type of primary malignant tumor, which demonstrates an extremely poor prognosis, despite combined therapeutic strategies $(17,18)$. A recent large-scale study reported that factors associated with adverse prognosis in ICC included positive margin status, multiple lesions, T category, lymph node metastasis and vascular invasion (18). Similarly, we identified that $\mathrm{T}$ category, lymph node metastasis, tumor stage and vessel invasion were significantly associated with patient survival.
Developments in molecular techniques have improved our understanding of carcinogenesis in CC and confirmed the role of biomarkers, including mucins and $\mathrm{Ks}$, in predicting a poor patient outcome (19). Ks are intermediate filaments that form part of the cytoskeleton in epithelial cells; there is increasing interest in their application as prognostic biomarkers $(19,20)$. Aishima et al identified that patients with ICC characterized by reduced K903 reactivity, which detects K1, K5, K10 and K14, displayed a significantly more favorable survival rate compared to those with preserved K903 reactivity (21). A high serum K19 fragment is associated with tumor progression and poor outcome in patients with ICC (22). The expression of K20 and its significance as a prognostic factor in ICC has not been elucidated. In the present study, the survival rate of patients with K20-positive ICC was lower than that of patients with K20-negative ICC; however, the difference was not significant. A longer term follow-up with a larger cohort is required to define the biological behavior of K20-positive ICC.

There is a strong correlation between the expression of mucin antigens and the survival of ICC patients (19). MUC1 is important in the invasiveness and metastatic potential of $\mathrm{CC}$, and usually correlates with a decreased survival (23-25). In contrast to MUC1, MUC2 acts as a protective protein and is associated with a more favorable prognosis $(26,27)$. MUC5AC is a gel-forming secreted mucin and serum MUC5AC is likely to be a poor prognostic factor in CC patients $(28,29)$. In the present study, MUC6 expression was a good independent prognostic factor in ICC, which is consistent with previous findings $(29,30)$. Further investigation is required to clarify the mechanisms of mucin expression associated with prognosis.

In conclusion, our study indicates that a proportion of ICC (35\%) retains K20 expression, and combined immunostaining for $\mathrm{K} 7$ and $\mathrm{K} 20$ is useful when making a differential diagnosis of ICC and metastatic CRC. K20 expression is also significantly associated with gender, location and macroscopic growth pattern of tumor, intestinal phenotype and MUC2 expression. Finally, we identified that MUC6 expression in ICC is a good independent prognostic factor.

\section{Acknowledgements}

This study was supported by the National Research Foundation of Korea Grant funded by the Korea government (No. 2011-0028223).

\section{References}

1. Moll R, Franke WW, Schiller DL, Geiger B and Krepler R: The catalog of human cytokeratins: patterns of expression in normal epithelia, tumors and cultured cells. Cell 31: 11-24, 1982.

2. Miettinen M: Keratin 20: immunohistochemical marker for gastrointestinal, urothelial, and Merkel cell carcinomas. Mod Pathol 8: 384-388, 1995.

3. Maeda T, Kajiyama K, Adachi E, Takenaka K, Sugimachi K and Tsuneyoshi M: The expression of cytokeratins 7, 19, and 20 in primary and metastatic carcinomas of the liver. Mod Pathol 9: 901-909, 1996.

4. Rullier A, Le Bail B, Fawaz R, Blanc JF, Saric J and Bioulac-Sage P: Cytokeratin 7 and 20 expression in cholangiocarcinomas varies along the biliary tract but still differs from that in colorectal carcinoma metastasis. Am J Surg Pathol 24: $870-876,2000$. 
5. Shimonishi T, Miyazaki K and Nakanuma Y: Cytokeratin profile relates to histological subtypes and intrahepatic location of intrahepatic cholangiocarcinoma and primary sites of metastatic adenocarcinoma of liver. Histopathology 37: 55-63, 2000

6. Edge SB, Byrd DR, Compton CC, Fritz AG, Greene FL and Trotti A (eds): AJCC Cancer Staging Manual. 7th edition. Springer, New York, NY, 2010.

7. Nakanuma Y, Curado MP, Franceschi S, Gores G, Paradis V, Sripa B, Tsui WMS and Wee A: Intrahepatic cholangiocarcinoma. In: WHO Classification Of Tumours Of The Digestive System. Bosman FT, Carneiro F, Hruban RH and Theise ND (eds). 4th edition. IARC Press, Lyon, pp217-224, 2010.

8. Moll R, Lowe A, Laufer J and Franke WW: Cytokeratin 20 in human carcinomas. A new histodiagnostic marker detected by monoclonal antibodies. Am J Pathol 140: 427-447, 1992.

9. Zen Y, Fujii T, Itatsu K, et al: Biliary papillary tumors share pathological features with intraductal papillary mucinous neoplasm of the pancreas. Hepatology 44: 1333-1343, 2006.

10. Nakanuma Y, Sasaki M, Ishikawa A, Tsui W, Chen TC and Huang SF: Biliary papillary neoplasm of the liver. Histol Histopathol 17: 851-861, 2002.

11. Zen Y, Sasaki M, Fujii T, et al: Different expression patterns of mucin core proteins and cytokeratins during intrahepatic cholangiocarcinogenesis from biliary intraepithelial neoplasia and intraductal papillary neoplasm of the bile duct - an immunohistochemical study of 110 cases of hepatolithiasis. J Hepatol 44: 350-358, 2006

12. Sugimachi K, Taguchi K, Aishima S, et al: Altered expression of beta-catenin without genetic mutation in intrahepatic cholangiocarcinoma. Mod Pathol 14: 900-905, 2001.

13. Hidaka E, Yanagisawa A, Seki M, Setoguchi T and Kato Y: Genetic alterations and growth pattern in biliary duct carcinomas: loss of heterozygosity at chromosome $5 \mathrm{q}$ bears a close relation with polypoid growth. Gut 48: 656-659, 2001.

14. Isa T, Tomita S, Nakachi A, Miyazato, et al: Analysis of microsatellite instability, K-ras gene mutation and p53 protein overexpression in intrahepatic cholangiocarcinoma. Hepatogastroenterology 49: 604-608, 2002.

15. Guedj N, Zhan Q, Perigny M, et al: Comparative protein expression profiles of hilar and peripheral hepatic cholangiocarcinomas. J Hepatol 51: 93-101, 2009.

16. Jain R, Fischer S, Serra S and Chetty R: The use of Cytokeratin 19 (CK19) immunohistochemistry in lesions of the pancreas, gastrointestinal tract, and liver. Appl Immunohistochem Mol Morphol 18: 9-15, 2010.

17. Jemal A, Bray F, Center MM, Ferlay J, Ward E and Forman D: Global cancer statistics. CA Cancer J Clin 61: 69-90, 2011.
18. de Jong MC, Nathan H, Sotiropoulos GC, et al: Intrahepatic cholangiocarcinoma: an international multi-institutional analysis of prognostic factors and lymph node assessment. J Clin Oncol 29: 3140-3145, 2011

19. Briggs CD, Neal CP, Mann CD, Steward WP, Manson MM and Berry DP: Prognostic molecular markers in cholangiocarcinoma: a systematic review. Eur J Cancer 45: 33-47, 2009.

20. Linder S: Cytokeratin markers come of age. Tumour Biol 28: 189-195, 2007.

21. Aishima S, Asayama Y, Taguchi $\mathrm{K}$, et al: The utility of keratin 903 as a new prognostic marker in mass-forming-type intrahepatic cholangiocarcinoma. Mod Pathol 15: 1181-1190, 2002.

22. Uenishi T, Yamazaki O, Tanaka H, et al: Serum cytokeratin 19 fragment (CYFRA21-1) as a prognostic factor in intrahepatic cholangiocarcinoma. Ann Surg Oncol 15: 583-589, 2008.

23. Higashi M, Yonezawa S, Ho JJ, et al: Expression of MUC and MUC2 mucin antigens in intrahepatic bile duct tumors: its relationship with a new morphological classification of cholangiocarcinoma. Hepatology 30: 1347-1355, 1999.

24. Park SY, Roh SJ, Kim YN, et al: Expression of MUC1, MUC2, MUC5AC and MUC6 in cholangiocarcinoma: prognostic impact. Oncol Rep 22: 649-657, 2009.

25. Matsumura N, Yamamoto M, Aruga A, Takasaki K and Nakano M: Correlation between expression of MUC1 core protein and outcome after surgery in mass-forming intrahepatic cholangiocarcinoma. Cancer 94: 1770-1776, 2002.

26. Hong SM, Cho H, Moskaluk CA, Frierson HF Jr, Yu E and Ro JY: CDX2 and MUC2 protein expression in extrahepatic bile duct carcinoma. Am J Clin Pathol 124: 361-370, 2005.

27. Tamada S, Goto M, Nomoto M, et al: Expression of MUC1 and MUC2 mucins in extrahepatic bile duct carcinomas: its relationship with tumor progression and prognosis. Pathol Int 52: 713-723, 2002.

28. Boonla C, Wongkham S, Sheehan JK, et al: Prognostic value of serum MUC5AC mucin in patients with cholangiocarcinoma. Cancer 98: 1438-1443, 2003.

29. Aishima S, Kuroda Y, Nishihara Y, et al: Gastric mucin phenotype defines tumour progression and prognosis of intrahepatic cholangiocarcinoma: gastric foveolar type is associated with aggressive tumour behaviour. Histopathology 49: 35-44, 2006.

30. Thuwajit P, Chawengrattanachot W, Thuwajit C, Sripa B Paupairoj A and Chau-In S: Enhanced expression of mucin 6 glycoprotein in cholangiocarcinoma tissue from patients in Thailand as a prognostic marker for survival. J Gastroenterol Hepatol 23: 771-778, 2008. 